Article

\title{
Floodopoly: Enhancing the Learning Experience of Students in Water Engineering Courses
}

\author{
Manousos Valyrakis ${ }^{1, *(\mathbb{D})}$, Gaston Latessa ${ }^{1,2} \mathbb{D}$, Eftychia Koursari ${ }^{1,3}$ and Ming Cheng ${ }^{4}$ \\ 1 Water Engineering Lab, School of Engineering, University of Glasgow, Glasgow G12 8QQ, UK; \\ Gaston.Latessa@jacobs.com (G.L.); Eftychia.Koursari@amey.co.uk (E.K.) \\ 2 Jacobs, Principal Hydraulic Modeler, Water and Environment, Glasgow G2 7HX, UK \\ 3 Amey Consulting, Structures, Glasgow ML1 4UR, UK \\ 4 Faculty of Education, Edge Hill University, Ormskirk L39 4QP, UK; ChengM@edgehill.ac.uk \\ * Correspondence: Manousos.Valyrakis@glasgow.ac.uk
}

Received: 22 December 2019; Accepted: 6 February 2020; Published: 8 February 2020

\begin{abstract}
This study focuses on the utilisation of lab-based activities to enhance the learning experience of engineering students studying water engineering and geosciences courses. Specifically, the use of "floodopoly" as a physical model demonstration in improving the students' understanding of the relevant processes of flooding, infrastructure scour and sediment transport, and improve retention and performance in simulation of these processes in engineering design courses, is discussed. The effectiveness of lab-based demonstration is explored using a survey assessing the weight of various factors that might influence students' performance and satisfaction. It reveals how lab-centred learning, overall course success is linked with student motivation and the students' perception of an inclusive teaching environment. It also explores the effectiveness of the implementation of student-centred and inquiry-guided teaching and various methods of assessment. The analysis and discussion are informed by students' responses to a specifically designed questionnaire, showing an improvement of the satisfaction rates compared to traditional class-based learning modules. For example, more students $(85 \%)$ reported that they perceived the lab-based environment as an excellent contribution to their learning experience, while less students (about 57\%) were as satisfied for a traditional class-based course delivery. Such findings can be used to improve students' learning experience by introducing physical model demonstrations, similar to those offered herein.
\end{abstract}

Keywords: laboratory demonstration; physical modelling; flood risk assessment; sediment transport; infrastructure scour hazards; outreach; water engineering

\section{Introduction}

Students have an inherent ability in learning and adapting to their continuously changing environment, and instructors have a role not only on offering knowledge to students, but also in developing their ability to learn more efficiently. One learning strategy that may be followed in doing so involves increasing students' desire to learn, by engaging students with questions before arriving to an answer, according to [1,2]. Considering that one of the essential first stages for knowledge discovery is observation, it is useful to enthusiastically engage with the students with lab demonstrations early in the course, in helping to educate the future engineers and geoscientists. Topics such as fluid mechanics and hydraulic and water engineering can highly benefit from such practices, as demonstrations of first principles on which engineering designs or physical processes are based may involve simple bench top to more elaborate flume demonstrations. For example, such phenomena may be mixing of fluids at different flow rates, as Osborne Reynolds did in his famous 1883 experiment [3]. 
A dynamic learning environment is in alignment with the perspective presented in a quote usually attributed to Socrates: "Education is the kindling of a flame, not the filling of a vessel". This can be best realized if one understands the need to continuously adjust and improve their knowledge, whether it is professional knowledge and experience or soft (e.g., communication) skills, to dynamically adapt to a constantly changing techno-economical and socio-political environment. Physical model demonstrations can allow the students to practice these skills by allowing them to work collaboratively towards inquisitive critical thinking for building their knowledge more effectively. A collaborative environment, where all students freely contributed their own perspectives and are welcoming of each other's views, as well as learning by mistakes, while participating in an open discussion about the best possible methods and tools to be employed towards problem solving, offers an ideal setting. This is because this approach exposes the individual to the collective intelligence of their group and allows them to efficiently achieve a better understanding of the mechanics and processes involved in reaching a solution, thus contributing more to their own learning experience compared to just working on their own.

Physical model demonstrations can also allow for teaching to be more student-centred, fostering active learning. Developing active learning strategies can be realized by implementing a student-centred approach to teaching and using visually rich and engaging lecture presentations, informative lecture notes and tutorials. During the lecture students can be asked questions and offered empirical paradigms relevant to the discussed topic or relevant research to cultivate students' engineering intuition. Asking students questions is very important, as it will improve students' metacognition as well encourage them to take a more active role in their learning [4]. This can also be achieved with the use of more modern technologies involving field work [5] or "virtual laboratories" [6-10], taking advantage of advances in the fields of virtual reality or augmented reality, as an alternative to physical laboratories. However, these technologies are yet not highly accessible for large cohorts of students, are relatively costly and require technical knowledge in using these and developing demonstration applications. Thus, the "floodopoly" setup, as the first author's own invention, is discussed and presented in this research study, as a tool aiming at improving the learning experience of engineering students, as well as engaging pupils in STEM themed subjects.

Student-centred learning has been proved as being effective in encouraging deep approaches to learning and in making students take responsibility for their own learning [11]. Focusing on students, as individual practicing engineers will help them to self-identify and develop their own talents as well as achieve a better understanding of how their unique skill sets and personality will fit in and potentially benefit their peer group's dynamics and performance. Focusing on developing students' strengths is an inherently energizing process for them, and allows the individuals to be in the flow zone of learning (appropriately challenged and motivated), allowing them to feel nurtured into developing as well rounded professionals and future leaders in their fields.

Over the last decade the above concepts have been deployed in shaping the delivery of modules in fluid dynamics, hydraulics and water engineering [12], for diverse cohorts and educational systems, including Virginia Tech (USA) and University of Glasgow (UK), such as the Environmental Fluid Mechanics (CEE3304) and Engineering Hydraulics 3 (ENG3085), respectively. Successful teaching should encourage and develop students' ability for active learning, a belief which, according to the current teaching practice for these courses, is influenced by perspectives early presented by Greek philosophers, such as Socrates, on learning. Specifically, according to the quote usually attributed to Socrates, one "cannot teach anybody anything, but can only make them think". Highly engaging teaching for fluid dynamics-themed courses commonly employ physical model demonstrations and can be even more impactful if their delivery is student-centred, with the students actively encouraged to maintain a sustained engagement and self-motivation towards knowledge and skills development learning, with strong focus on the development of each individual's strengths (which requires a diverse way of assessment). The value of physical model or lab-based demonstrations in introducing a student to the scientific method, the observation of a system or process of interest, the formulation of a 
research hypothesis and the design of an appropriate framework is indispensable. This can be done by discussing with the students the methods researchers use to build a wealth of scientific information by means of observing physical processes, encouraging them to reproduce experimental results and suggesting how to demonstrate their critical thinking. This approach helps equip students with appropriate tools to carry out research in the future as academics or gain confidence as engineering professionals, as [13] have demonstrated.

Here the use of a physical lab demonstration is presented as one of many student-inspiring demonstrations offered within our UK-wide top degree program in Civil Engineering at the University of Glasgow (ranking top three across the whole UK over the years 2017-2019, and first in 2019, according to the National Student Survey). A distinct feature of this degree is the significant amount of design-centred and practical skills development-oriented courses, many of which involve lab-based or computer demonstrations. In addition, a low staff-to-student ratio, a high entry level for the students and the fact that the University of Glasgow is a research-intensive environment contribute to building an identity as an engineering researcher or innovator; becoming a "world-changer" as the university community prides. Small-group teaching is found to help develop an active learning environment, as the instructor has a better chance for clarifying points made in lectures, helping the students gain a more comprehensive understanding and fostering discussion and communication of ideas [14]. The contained size of the class and lab-based sessions (split into small working groups of four to eight undergraduate students each) works well in helping to encourage discussion of problems and seeking peers' feedback.

Specifically, the use of a novel physical demonstration, namely "floodopoly", as part of a design class, which aims to introduce to the students the principles of flood risk modelling and assessment, is detailed herein. The course in which the "floodopoly" demonstration is introduced involves a problem-based learning environment, and it focuses on developing higher cognitive functions, for example, critical thinking, encouraging problem solving and bringing exciting and tangible lab-based research observations into the course. Such a course design, that links teaching with research, is shown as effective in extending beyond traditional student knowledge, by empowering students and advancing intellectual curiosity [15]. Further, research-based course design has been associated with deep, rather than superficial, student learning $[16,17]$, and is believed to have the potential to improve students' satisfaction and benefit students' professional development. The results from a survey offered to the students are further discussed to demonstrate how physical demonstrations are contributing to an enhanced student learning experience.

\section{Physical Model Demonstration}

The main goal of the "floodopoly" physical model demonstration is to allow the students to observe the physical mechanisms of flooding, which students are assessing later through numerical modelling. This hands-on, active learning student-centred experience facilitates their grasping of key aspects of flooding and associated hazards, in urban environments.

\subsection{Experimental Setup}

"Floodopoly" is an interactive demonstration aiming at allowing the students to play out a number of scenarios, simulating the effects of rising hydrograph and flow unsteadiness in a physically relevant and engaging manner, towards knowledge discovery. This allows the students to have a significantly improved understanding and intuition-led critical thinking for the studied dynamical processes, before embarking on using appropriate software (such as HEC-RAS) for flood modelling and flood risk assessment, in the later part of the course.

A number of improved designs have been utilised over the many years, but there are essentially two versions of the "floodopoly" setup; (a) a versatile mobile setup (Figure 1a) and (b) a permanent one (Figure 1b). Both setups involve a fit-for-purpose model city in a sandbox, which is already built for the demonstrations as described in the following. The model city uses building blocks from Lego ${ }^{\circledR}$ 
along with custom paper-made or 3D-printed physical models of built infrastructure to simulate a typical built environment. Means of transport (such as vehicles, buses and trucks), elements of the natural environment (such as trees) and built infrastructure (houses and skyscrapers), including iconic buildings, such as the Eiffel tower and Parthenon (Figure 1a), or the London Eye and Big-Ben (Figure $1 b$ ), are all scaled to fit within the sandbox model city and can be featured for enhanced dramatization during the demonstration.

The mobile "floodopoly" version (Figure 1a) has a 3D-printed topography of the model city and complex river geometry, allowing the floodplains to be covered in water impacting infrastructure in the extreme hydrologic scenarios. The water tank of the setup is made of transparent $7 \mathrm{~mm}$ thick acrylic panels and comprises of a tank with external dimensions of $90 \mathrm{~cm}$ length, $50 \mathrm{~cm}$ width, and 30 $\mathrm{cm}$ height. Blue-dyed water is circulated through the model for the demonstrations to improve the visualization of the flooding process. This water is then collected "downstream" so the experiment can be run again. The sandbox containing the 3D-printed model surface replicating the complex topography of the model city, involving a river and its floodplains, is of slightly smaller dimensions, allowing for recirculating water on its surface through an appropriately constructed inlet (aligned with the river's main channel) using a configurable pump introduced at the water tank of the setup. Focus is given on producing a visual effect on the impact of flooding, so some of the built infrastructure and monuments can be purposely placed at or near the floodplains. After the demonstration, water can be drained from a small outlet valve attached at the lower corner of the acrylic box.

The lightweight, modular arrangement (all items such as the built infrastructure and 3D-print surface topography are also lightweight and removable) and small size of this setup allows it to be easily carried to a specific location for engaging with target audiences, beyond the classroom. This versatile setup has been successfully presented to thousands of pupils and students during recruitment events (such as the School of Engineering Open days), as well as outreach events (such as Widening Participation schemes, Glasgow Science Festival, Glasgow Science Museum). It can also be shown in an open-air classroom next to the river Kelvin (within walking distance from the classroom) for the Engineering Hydraulics classes and Civil Design project, for third and fourth year engineering students.

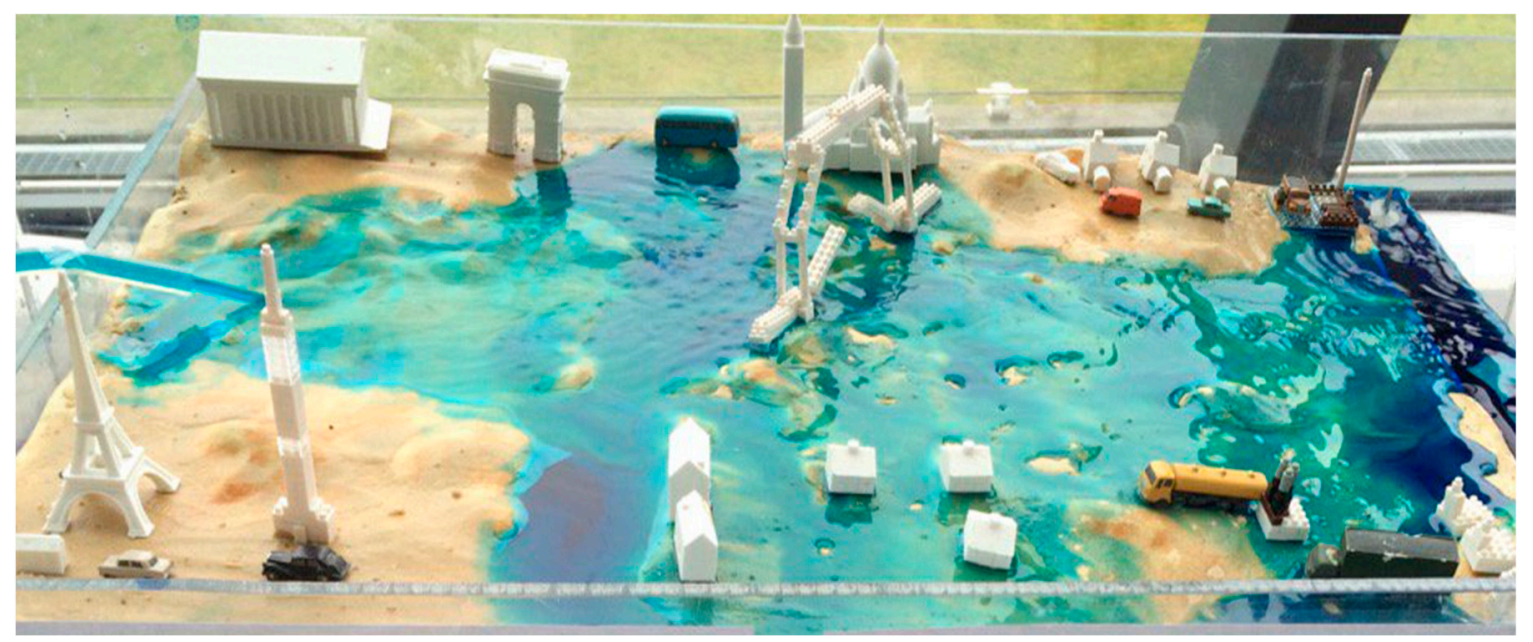

Figure 1. Cont. 
(a)

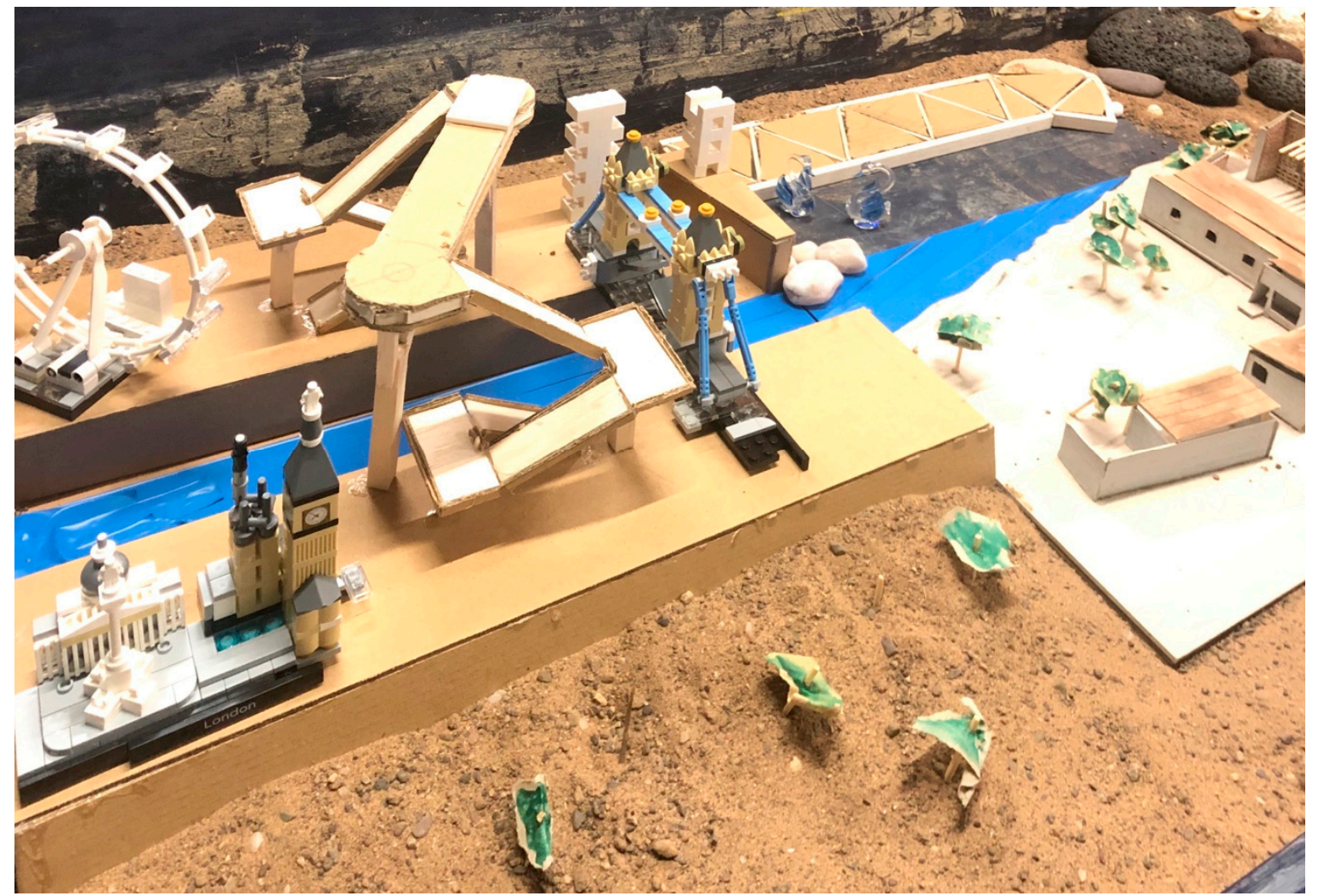

(b)

Figure 1. Demonstration of the "floodopoly" demonstration: (a) The flooded state of the mobile setup, at the "meet the experts" session (during the Glasgow Science Festival 2016, at the Glasgow Science Centre); and (b) the dry state of the permanent (flume-based) setup, at the Water Engineering Lab of the University of Glasgow.

The permanent design (Figure 1b) involves replicating part of the river Thames and the relevant infrastructure along it. The model city is built with Lego ${ }^{\odot}$ inside a standard Armfield-type demonstration flume repurposed specifically for this project. The flume is substantially longer (7 m long in total) and $60 \mathrm{~cm}$ wide, while much bigger flow rates can be run in a recirculating fashion. Both setups have flows running through the river via the use of small pumps of controlled flow rate to simulate a rising or decreasing hydrograph. The students are encouraged to replicate an extreme flash flood scenario by pouring large volumes of water at a fast pace, aiming to demonstrate the dramatic impacts of flooding, resulting in highly-visual damage to built infrastructure, and activation of floodplains in routing the flood. The topography of the models can be sprinkled with sand of different sizes to also demonstrate scour and sediment transport processes and how increased flow or shear flow forces can result in increased rate of transfer of smaller or coarser grains, helping the students understand that coarser grains can generally withstand increased stresses, thus are more suitable for use in hydraulic protections and armouring infrastructure near water.

\subsection{Demonstration Protocol}

Both of the above setup versions can be used to run the "floodopoly" demonstration in an interactive manner. More complex game mechanics can be further introduced depending on the time allowed for the demonstration, thus the name is chosen to rhyme with the popular game monopoly ${ }^{\odot}$. The following steps are offered as an indicative guidance to the demonstrator. 
Firstly, the demonstration space is introduced and any important health and safety issues are presented, along with a brief summary of the demonstration, as an interactive, hands-on experience for students to investigate the impacts of flooding, and to develop a first understanding of flood defence designs, by means of tangible observation of the involved hydraulic and geomorphic processes.

Secondly, the audience is familiarized with the different model city areas, including the historical areas (model castles and churches), energy related facilities (model coal extraction and oil and gas facilities), industrial plants (behind the model floodwalls), housing areas and residential properties, and hydraulic infrastructure including model bridges, roads/highways and locks.

Thirdly, the impacts of flooding and scouring of infrastructure are presented. Flood risks associated with floods, such as loss of life and infrastructure costs, are discussed. Emphasis is given at the fact that floods have been always happening, but because of increased urbanisation and climate change, societal catastrophic impacts due to floods have continued increasing at an alarming rate. In an inquiry-led session, the students are asked to consider which areas are more flood-prone and what makes them more susceptible to flooding.

The processes of scour [18] and sediment transport are discussed. For example, the demonstrator can introduce some additional fine and coarser sediment, across the setup, and ask the students to observe the locations and the size of sediment in relation to eroding and settlement. The students are allowed to think out loud and discuss with each other their observations, towards identifying the first principles around these physical processes in a collaborative manner. A further inquiry can be around devising ways by which such first principles can be used to design engineering against scour, eventually observing that, in the real world, engineering practitioners use coarser sediment as rip-rap. Since pier shape can also affect the scour geometry [19-21], this installation may be used to demonstrate influence of pier shape on scouring process, by placing piers with different shapes inside the fluvial model.

To further enhance the students' tangible observation-led learning of the physical processes, as well as the impact of flooding on the environment, infrastructure, people and their property, two more highly-interactive role-playing scenarios can be run:

\section{The Scenario of Urbanisation}

Individual students from the participating audience are given the same number of 3D-printed miniature houses (similar design to what is found in the housing blocks of Monopoly ${ }^{\odot}$ ) and assume the role of citizens and engineers contributing to the development of the city's floodplains. The students are asked to take turns in placing one of their buildings on one of the many predefined plots for development on the floodplain. The demonstrator describes that during this scenario the city gets increasingly urbanised over a period of cycles, as each of the student is occupying a new plot with their building. The students are asked to contemplate and consider the first physical principles discussed earlier towards identifying which of these plots could face a greater risk of flooding. Naturally, most of the students will opt for the higher ground, and, as such, plots become less available, other principles will have to be employed, such as avoiding building next to a segment of the river with low slope, as the flow depth (for the same river geometry and flow rate) will have higher flow depth (thus a higher risk of flooding).

The mechanics of the interactive demonstration can be further gamified, but the focus here is rather on collaborative learning by means of observation. Even though the demonstration is student-centred, the demonstrator is guiding and pacing the process by inquiring, for example, about the students' expectations as the flow rate increases and asking students to identify the areas with greater risks. As the floodplains get flooded, the students get a chance to seriously reflect on their choice, as if their own property had flooded in the real world. This also stimulates their sense of responsibility as an engineer. Last, the students are offered a chance to identify direct (e.g., by placing floodwalls, embankments, channel geometry modification) or indirect protection measures (e.g., having an upstream storage scheme or changing the land use around the catchment, by planting more vegetation to slow the surface runoff before it becomes accumulated stream-flow). 


\section{The Climate Change Scenario}

In this scenario the students are asked to simulate extreme hydrologic events, due to climate change. They are given plastic cups of different sizes (thus varying the volume of water to be dropped), prefilled with blue-dyed water, and are allowed to spill it at the upstream end of the river, running already with the highest base-flow. The students can empty their cup as fast or as slow they desire, observing that the rate of volume offered to the base-flow rather than the volume alone is important in defining the change in the hydrographs. As they observe the peak of the hydrograph upstream propagate downstream, they also have a chance to observe the attenuation of the peak flow rate. This is the most visually impactful part of the demonstration, with many students enjoying the activity of flooding the landscape of the sandbox and impacting infrastructure within it. As the pressure from climate change is rapidly increasing, a whole scenario is purposely devoted to demonstrating its potentially catastrophic impacts. Given that the nature of this physical demonstration is to generate a visually-induced emotional response around the increasing frequency and magnitude of hydrologic events, it is purposefully involving a qualitative rather than a quantitative comparison.

\section{Results}

\subsection{Design Course Background and Assessment}

A range of both formative and summative assessment methods are used in the design course where the "floodopoly" demonstration is offered, which proves to be effective in improving students' learning [22]. Specifically, assessment methods range from assigning extra credit quizzes at the end of each lecture to performance assessment quizzes and assignments on a weekly or bi-weekly basis. Assigning customized exams and quizzes as well as a final project report helps them by enhancing their writing and reporting skills and improving their critical thinking capacity, allowing them to progress in more advanced topics. The use of a flexible assessment scheme for the final presentation of their output, where one has the option to prepare a video, a poster or oral presentation, allows a student to capitalize on what they perceive to be their strength and feel greater satisfaction. Based on student feedback, the offered assessment methods are suitable and the diversity of assessment methods and the opportunity to reflect and identify their own strengths is appreciated.

\subsection{Student Survey}

To assess the effectiveness of the "floodopoly" demonstration as a novel highly visual and tangible way for reinforcing inquiry-led learning, a purpose-designed questionnaire is offered to the students. The use of questionnaires as a data collection method is well established and has often been used for course evaluation [23]. A total of 25 out 30 students completed the questionnaire in full, after the completion of the course. Specifically, the questionnaire covers several aspects that affect student learning, performance and satisfaction, such as students' motivation, factors to effective learning (also assessed by follow-up quizzes) and methods of communication and assessment; in an effort to identify how a physical demonstration may be a more engaging and beneficial learning activity compared to other options, towards better achieving the intended learning objectives of the course within a broad context of the engineering and geosciences curriculum. The presentation of results is given in the following main themes explored below: (a) Students' motivation for attending the water engineering courses, (b) effectiveness of course environment and material offered, (c) suitability of methods of communication, (d) learning and assessment methods and (e) assessment of level of difficulty, performance and overall satisfaction.

\subsubsection{Students' Motivation for Attending the Water Engineering Courses}

The first set of questions aims to access one of the most important aspects of learning-the level of motivation and enthusiasm for the theme studied. Motivation can affect attendance and focus during the class and can depend on the how each student perceives the course to be useful to their 
professional development. Student replies are visually offered by means of word clouds showing the most frequently used words by students per question (Figure $2 a-d$ ).

Regarding students' perception of their future role as civil engineers (question a1), most replies involved design and construction (building) of infrastructure, as well as problem solving applied to challenging aspects of our society, which are indeed amongst the most fundamental aspects of civil engineering (Figure 2a). Some replies are original and indicative of a high level of inspiration "civil engineer = builder of dreams", while several (at least three) other students chose to identify with known quotes of the role of the civil engineers (e.g., "Harness the power of nature for the greater good of mankind").

For the second question (a2), on what excites them most about the profession they study, answers signifying intrinsic or extrinsic motivation to different levels are observed (Figure 2b). Replies, such as "fulfilment from design to structure completion" and "the opportunity to be part of the design or construction of a landmark, or design to improve the life of people", show a high level of intrinsic satisfaction expected by the practice of this profession. From this question, several highly-motivated students can be identified due to extrinsic factors, such as "being part of a well-known project and opportunity to travel abroad" which reveals focus on external rewards (influence, esteem and travel).

Replies from the next question (a3: "What do you aspire to do in 5 to 10 years from now?") covered virtually all disciplines of civil engineering, namely, structural, water/environmental, geotechnical and transportation engineering (Figure 2c). Most students confidently reported they wish to eventually secure "chartered" status with a professional body, as can also be seen from the word cloud (Figure 2c). More students showed an interest to work in industry/consultancy, than government and NGO's.

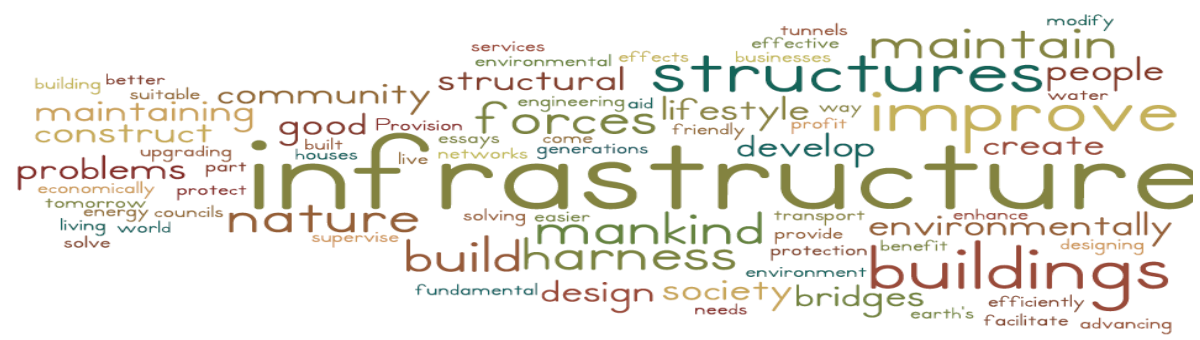

(a)

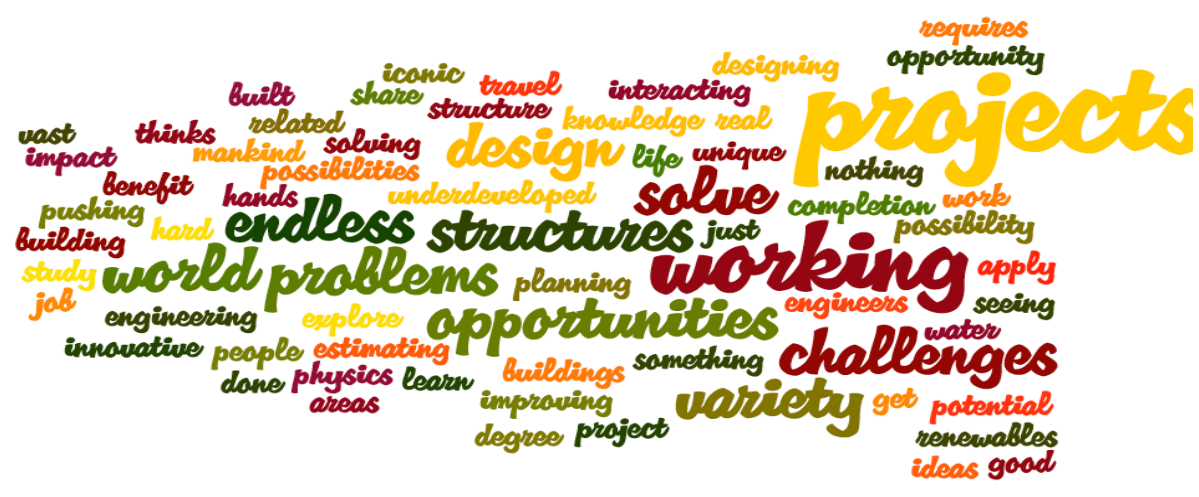

(b)

Figure 2. Cont. 


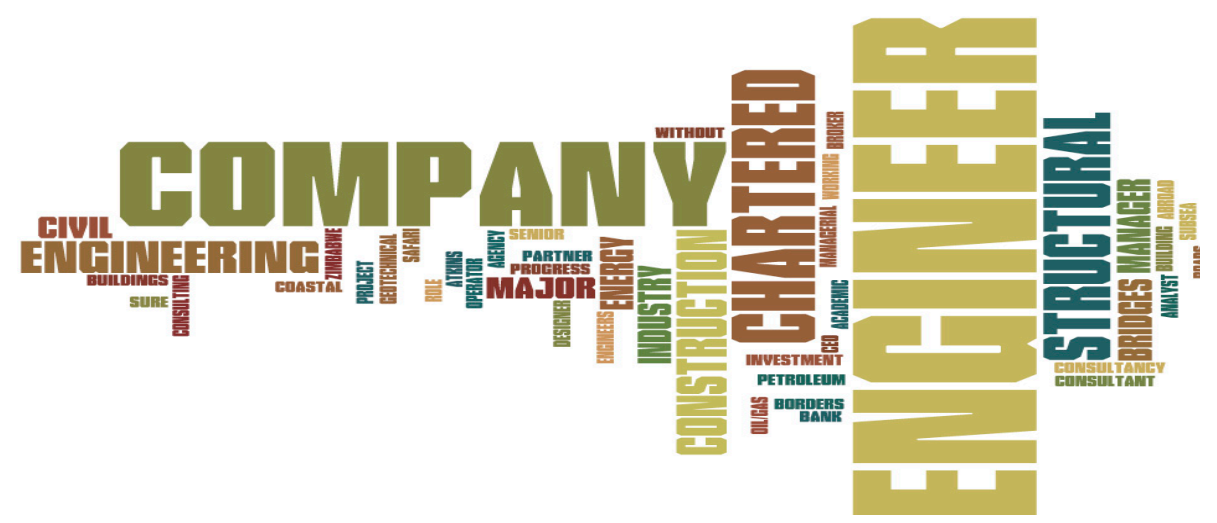

(c)

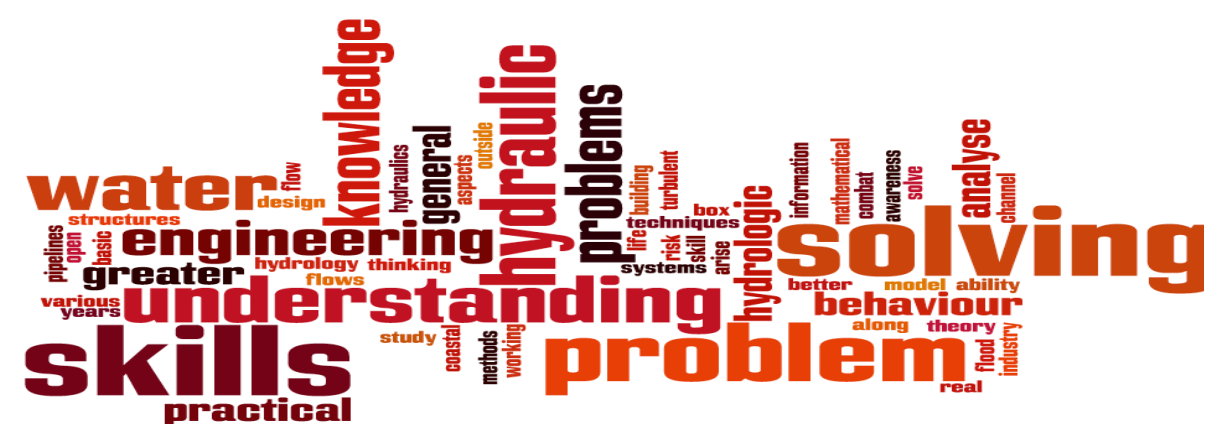

(d)

Figure 2. Word cloud representation of collective replies from the first part of the questionnaire assessing the students': (a) Role as professionals, (b) motivation, (c) career aspirations and (d) expectations from this course.

With regard to the students' expectations for this course (question a4), the replies were centred around both skills and knowledge to be gained (Figure 2d). The former ranged from group work, report writing and problem solving to the ability to utilise effective modern computational tools and techniques, while the latter involved extending the fundamental theoretical background with reference to practical experience and best practices from real life problems. Indicative is the following student reply, demonstrative of a need to link the taught material with the professional practice, while enriching their interest on the discipline: "Practical knowledge of water engineering and give me something I can actually use in my professional career. I hope to build on my interest and passion for the subject".

\subsubsection{Effectiveness of Course Environment and Material Offered}

The following set of questions (b1-b3) focus on the perceptions of student's knowledge, aiming to explore the confidence of an individual in thinking about each specific question rather than assessing the true knowledge on this (for which a test/quiz type of question would be required, and which is explored in sequent questions). The specific questions (SQ1-SQ6) are representative of each of the six course objectives and thematic sections that the students were taught in class. As seen from Figure 3a, on average the students feel confident with the overall level of understanding they have acquired during the taught course (average for overall knowledge is 3.4, on a scale from 0 to 5 , with 5 being excellent). The students can answer fundamental theoretical questions with more confidence (SQ2, SQ3, SQ5), while more advanced (SQ4) or abstract (SQ6) concepts, requiring critical thinking, were ranked relatively lower. It is interesting to note that while the standard deviation for the first few questions ranges from 0.7 to 0.8 , it is above 1.1 for the last one (SQ6), showing that some students felt less equipped in higher cognitive skills compared to others. 


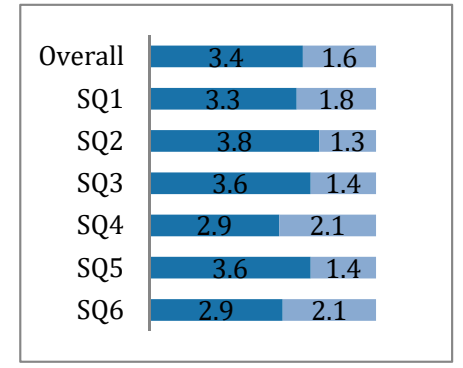

(a)

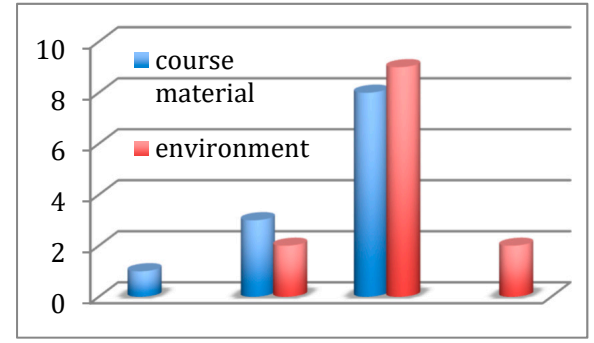

(b)

Figure 3. Students' perception of the: (a) Knowledge gained during the course (assessed on a scale from 0 to 5). The students are queried in relation to their overall knowledge first and then specific questions about their disciplinary knowledge (SQ1-SQ6) and (b) course material and environment (ranging from neutral (left) to excellent (right)).

The next two questions concern student satisfaction with the course material, including notes posted online (e.g., Moodle) or handouts distributed in the class and the lab sessions (b2), as well as the environmental factors during these sessions including the lab-based demonstrations (b3). The feedback offered is summarized in Figure 3b. Even though it is observed that the overwhelming majority of the students who answered indicate their high level of satisfaction with both factors, the shift of the distribution to the left demonstrates clearly that the use of the lab for physical model demonstrations is even more appreciated and valued, compared to only teaching in the classroom. Specifically, about $85 \%$ of the students perceived the lab-based environment as a great or excellent contribution to their learning experience, while fewer students (about $57 \%$ ) were as satisfied for a traditional class-based course delivery.

\subsubsection{Suitability of Methods of Communication}

Following, the utility of other means of communication and updating students on course content and feedback (in addition to Moodle and e-mail) is inquired (c1-c3). It is interesting to note that many students choose such modern platforms for this goal, many accessed at least on a daily basis or more often. This view is supported by the results illustrated in Figure 4a, where the various online means students frequently use and would be willing to use for the purposes of class communication are shown. Facebook ranks second in popularity (with 16 students, half of whom prefer very frequent communication) compared to the online web pages and blogs (with 20 students). Only a few (six) of the students believe there is a need to establish a Facebook group page for such purposes (Figure $4 \mathrm{~b}$ ). On the contrary there are many who feel this is not required as " ... Moodle and email is sufficient for the class needs" or even a few who may feel even stronger and stating an opposition in subscribing to such services "due to the terms of use". Thus if an inclusive method is to be used, Moodle and email suffice for reaching out to the class. The optimal frequency to contact students varies greatly from "every other day" to "only when needed", with more than half of those who answered, believing that it is best to be contacted at least once a week (Figure 4c).

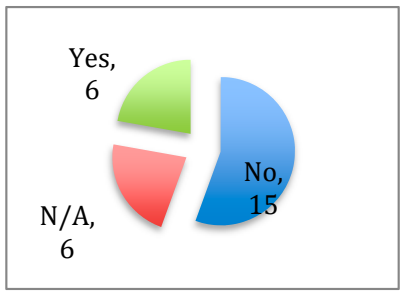

(a)

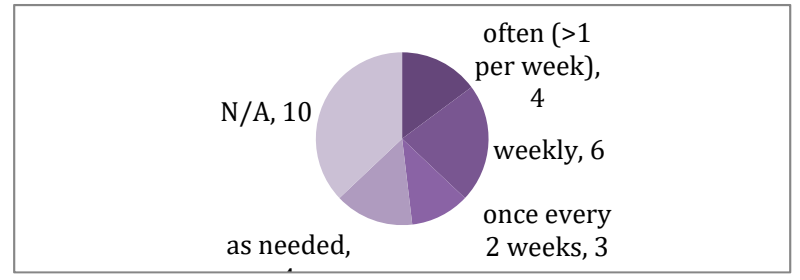

$(\mathbf{b})$

Figure 4. Cont. 
many times daily $\quad$ daily $\quad$ several times per week

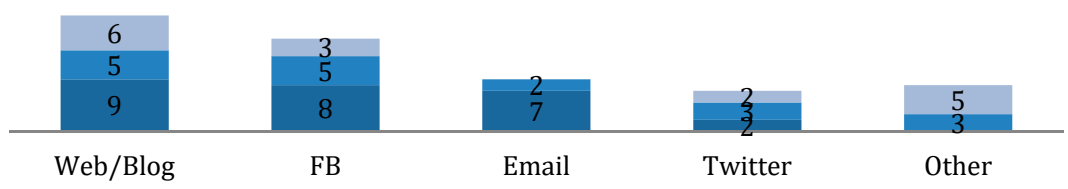

(c)

Figure 4. Students' perception of: (a) The utility of a Facebook (FB) group page for the course, (b) the optimal contact frequency for receiving course updates and feedback, and (c) the overall utility of online platforms on class communication and feedback.

\subsubsection{Learning and Assessment Methods}

Two important questions follow $(\mathrm{d} 1-\mathrm{d} 2)$ pertaining the methods of assessment, beyond the traditional exam-based assessment that is employed for this course. Figure 5a shows the results grouped per type of assessment and percentage contribution for each (out of a total of 100\%). Students are allowed to choose more than one option, with the most popular ones being lab work, home assignment and technical reporting for about $10 \%$. This is consistent with the students' desire to learn hands on, practical skills at the lab as well as improving their problem solving and technical writing skills, respectively. Fewer preferred the presentation with slides, as unfortunately at this level they may have not gained the experience required to present with confidence, as opposed to later years. It is generally agreed that the course assessment should not be entirely exam-based. The importance of addressing the need to use a versatile scheme that includes different assessment approaches and which allows the individual to reflect on their own skills, putting emphasis on growing their own skills/talents, is also reflected below with only one individual being indifferent and most of those who replied believing it is imperative (Figure 5b).

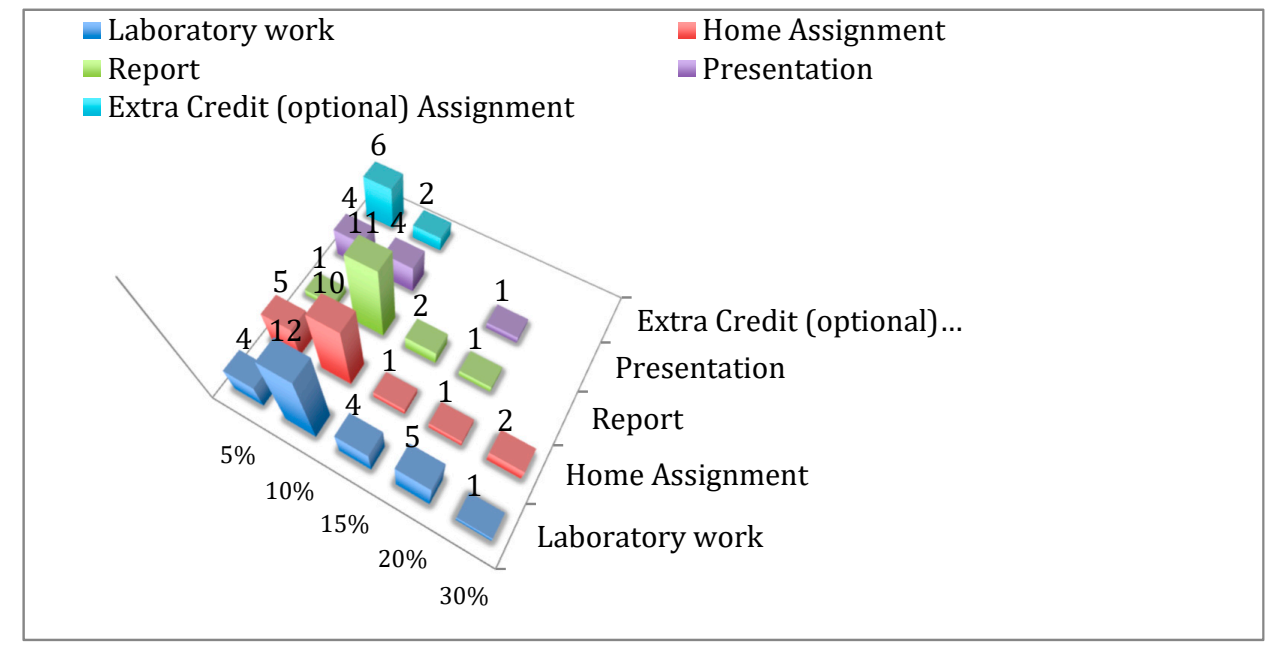

(a)

Figure 5. Cont. 


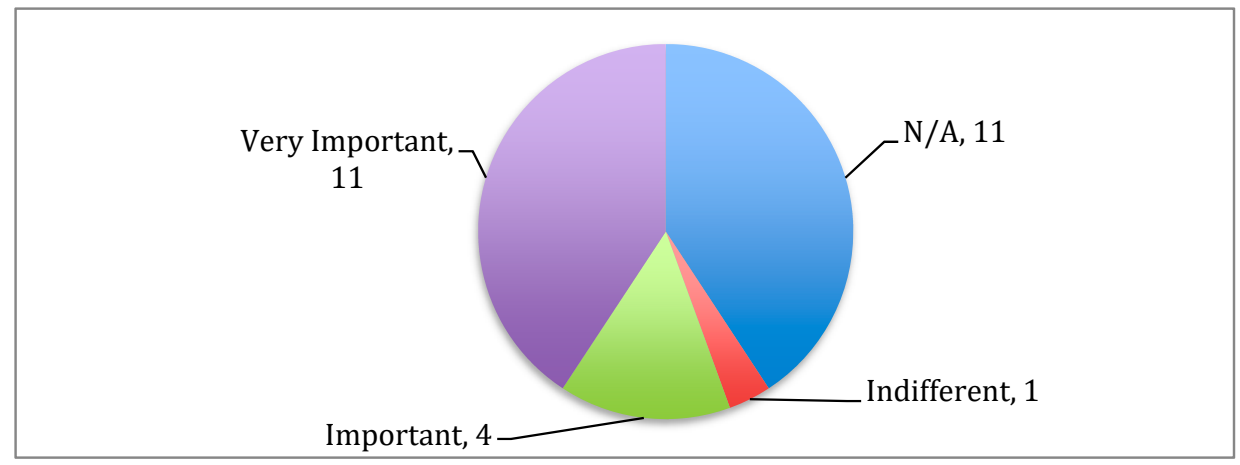

(b)

Figure 5. Students' perception of the: (a) Usefulness of a variety of assessment methods and (b) importance of adopting a versatile scheme for assessment.

\subsubsection{Assessment of Level of Difficulty, Performance and Satisfaction with Individual Performance}

The last three questions (e1-e3) relate to the perceived difficulty for the class (a measure relevant to expected individual performance or how challenging the course is, compared to other courses offered), overall performance and degree of satisfaction with the overall grade achieved. More than two thirds of those who replied regarded the class to be generally quite more than challenging and "moderately hard", while only a third perceived it as being at an acceptable "average" level of difficulty (Figure 6a). The reported performance levels vary greatly covering the whole spectrum of grades, but with a good portion of high grades (Figure 6b). This is not unreasonable given that the exams cover material that has been seen by the students in class or tutorials, reducing the uncertainty over the questions that might be asked. Likewise, the satisfaction results (Figure 6c) demonstrate a degree of polarization with an about equal share for those who are satisfied and dissatisfied with their performance.

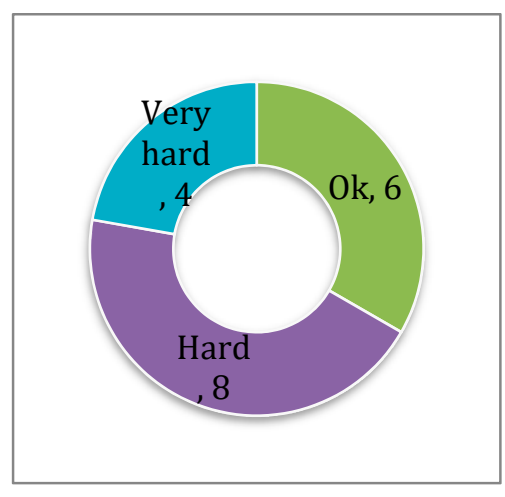

(a)

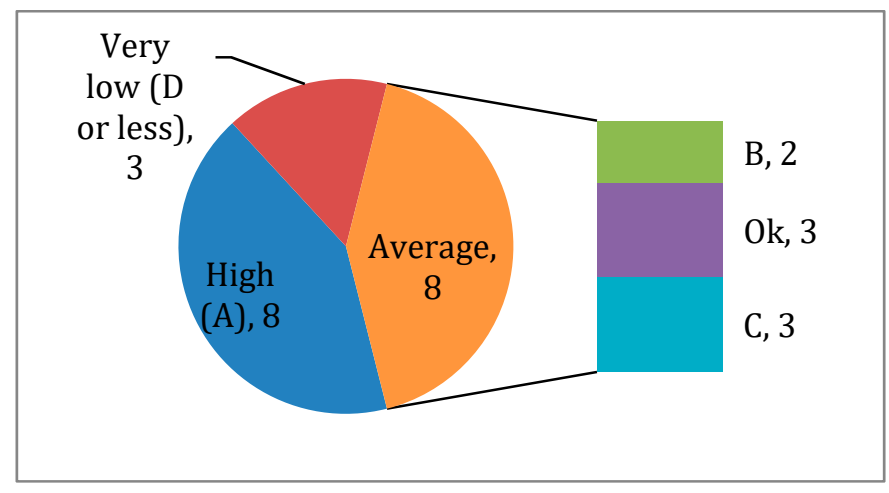

(b)

Figure 6. Cont. 


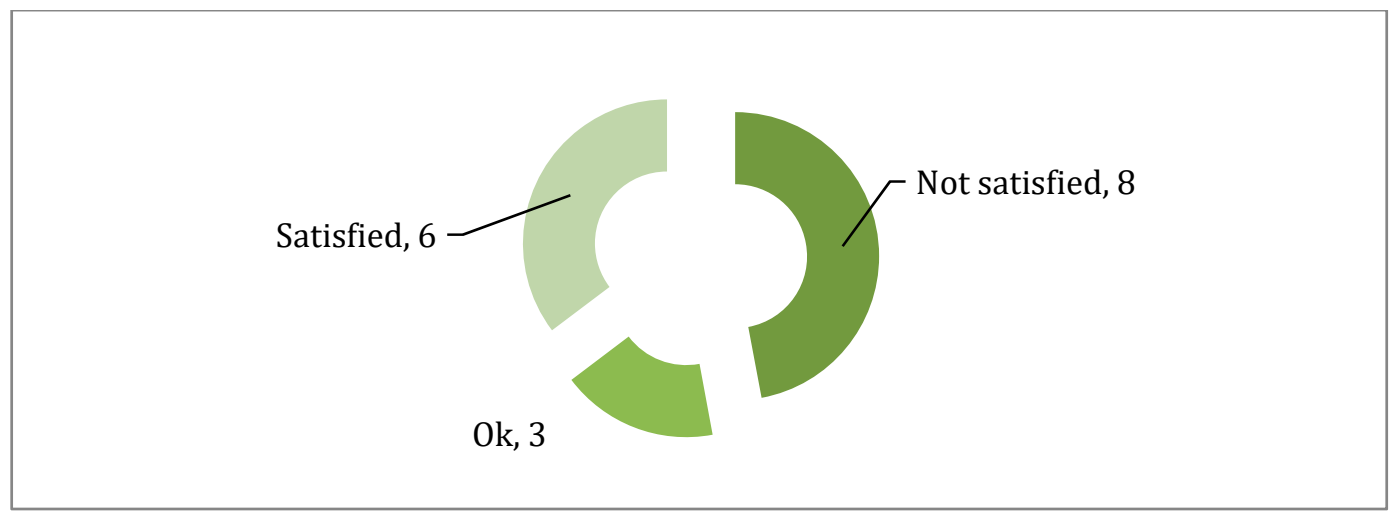

(c)

Figure 6. Demonstration of the students': (a) Perception of the difficulty of the course, (b) performance achieved overall and (c) own satisfaction with their individual performance at this course.

\section{Discussion}

The role of students' motivation on achieved learning outcomes can be further evaluated. The findings suggest that students' motivation could be either intrinsic or extrinsic. Students demonstrated well how they perceive their role as future professionals and they showed a great sense of duty. Examples of primarily extrinsic drive may be seen in replies to question a3, where some individuals were driven by professional status and income. Further, a good number of students (about 40\%) explicitly stated their interest or specific focus in water and environmental engineering in addition to other disciplines (such as structural and geotechnical), which signifies their particular interest for this class (Figure 7). A good correlation holds for those who stated explicitly primarily intrinsic motivation, along with specific aspirations. This demonstrates that motivation is an important factor in positively influencing the learning outcomes, which echoes the argument by Baeten et al. [24].

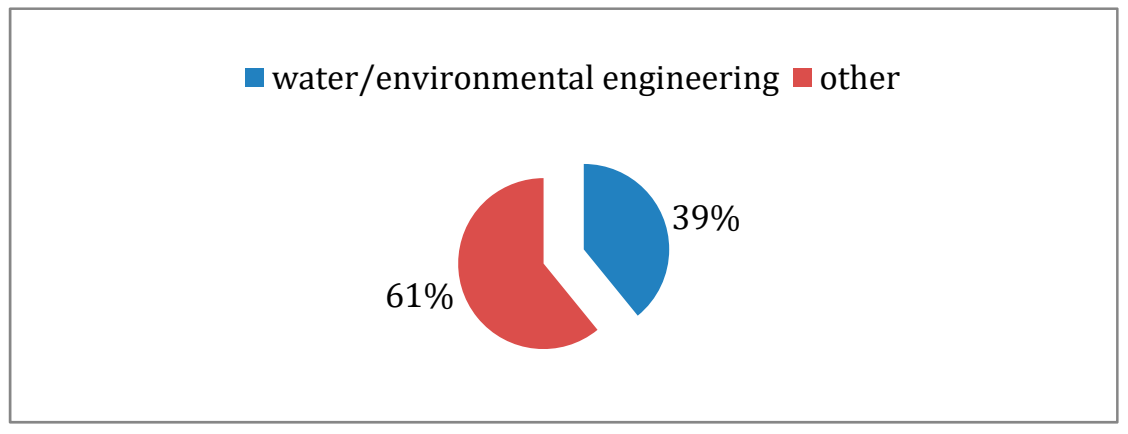

Figure 7. Students' focus on particular engineering disciplines.

Indeed intrinsically motivated students will typically tend to perform better than the rest of the students, as they work harder and more independently, regardless of the learning environment. However, a student-centred environment with highly-visual physical demonstrations, as those described herein, allows for accommodating a wider range of student learning styles, having a greater potential in ensuring that all students do even better, compared to a traditional learning environment. It is the belief of the authors that the time and effort put into the search for active learning strategies is valuable, given the increase in terms of both student satisfaction and experiential learning. Driven by a deep interest for the topic, the instructor can further support the development of a student focus group, consisting of actively engaged students who are motivated in utilising more of their potential while polishing some of their lab work, technical writing, teamwork and presentation skills. The group could be meeting on a regular (e.g., bi-weekly) basis to discuss/present active student projects, 
opportunities for volunteering or ongoing research in water engineering as well as promoting lab and research activities.

Kabilan et al. [25] argues for the use of Facebook to enrich the learning environment and to reach out to students more efficiently and timely. Even though it seems that some potential exists in the use of social media for effective teaching, the use of physical lab experiments is definitely more defining for promoting active learning, because students can feel present in an inclusive environment, receiving direct feedback and having the chance to interact in a focused manner. For example, if an environment is cultivated aiming at actively engaging with the students, then students will develop a deep learning approach $[22,26]$. By contrast, students are likely to focus on exams and performance, if the class is perceived as overly difficult with a high workload. Regarding the use of modern online technologies, such as Facebook, in alignment with students' replies, it is worth investigating the potential to assist learning, but only on a complementary basis and in addition to existing platforms currently in use (Moodle and email). Amongst the greatest advantages would be offering direct, timely and personalized course feedback. However, to facilitate learning the tool has to be fully integrated and promote the course objectives (e.g., with live links to video and other resources visible in the timeline) as the course progresses [25].

With regard to assessment methods, even though the exam retains a significant weight of the overall course grade (at least $60 \%$ ), having more options for assessment rewards the students who are consistent and deep learners, rather than those who simply prepare better for the exams. There have been some who expressed disappointment over the exam being "too short" or "did well in homework but messed up with final exam". So having more assessment components can relieve concerns due to a "hard" exam. Further, having a plethora of assessment methods delivered during the course allows many students to get involved and engaged to learn early on rather than just prepare for the exam, focusing on the grade as a goal to itself. Generally, good performance correlated well with satisfaction for the course, with the exception of one individual who reported being unsatisfied, despite the high grade (A4), as they know "more about the exam than the course". Evidently the students are overall quite confident in knowing well most of the specific thematic questions, long after the class had finished, which was demonstrative of deep learning achieved, as confirmed by Lizzio et al. [26] and Baeten et al. [24].

The students need be able to clearly see that assessment is strongly linked with the intended learning outcomes of the course, and that achieving these takes "time and effort" [27]. As many new students may get easily distracted in our technological era, it is important to encourage explicit interactive sessions that promote a deep learning approach according to Nicol [27]. It is also important to emphasize that extrinsically motivated students may not find value in undertaking assessments that do not contribute towards their final grade. Thus widening the range of offered methods of assessment, by using online quizzes as part of the summative assessment, can also help by offering timely constructive feedback. Well-designed online (Moodle) quizzes offer a great way to offer automated, direct feedback that enables students to act upon improving any mistakes (e.g., by allowing multiple attempts and offering a rationale on every wrong answer), helping to motivate and engage students [27].

To this goal, the role of lab-based demonstrations is of high value in achieving active student learning and offering a supportive, interactive and inclusive environment. The use of floodopoly has been demonstrated here for helping reinforce learning and promote the learning objectives of a design course on assessment and modelling of flood risk [28]. The activity described herein is part of a design project, which typically does not involve exams. However, the students in this Design Project as well as in traditional modules which involve other types of assessment (lab reports, assessments and exams) typically explicitly demonstrate a significantly high satisfaction rate for the part of the module involving the physical lab component.

"Floodopoly" is highly versatile and can also be used for outreach purposes, to showcase the detrimental impacts of flooding, for both natural ecosystems and built infrastructure (see relevant 
posts on Twitter https://twitter.com/WaterEngLab/status/758270564561784832 and Youtube https: //youtu.be/H5oThT6QaTc). Highly interactive sessions were used, whereby the students simulate the scenarios of "urbanisation" (by placing more buildings on the floodplains) and "climate change", where more extreme flow rates have to be routed through a greater extent of the floodplains, having even more catastrophic consequences. Using such novel student-centred demonstrations, the students are given a truly unique experience and are encouraged to appreciate engineering principles and design approaches towards installing contemporary flood protections for protecting the model city from extreme hydrologic events. This demonstration can be also combined with targeted research article reading on the processes of flooding and sediment transport $[29,30]$ to break down any access barriers in engineering innovation and promote students' confidence in understanding and eventually performing research. Students who took part in this taught module, and chose a relevant career to become hydraulic engineers or flood modelers, expressed their satisfaction and how much they have been positively impacted by the physical lab demonstrations and research-led component of the course. Indicative is the unsolicited statement of a recent graduate student, currently employed as a Graduate Engineer at a big international engineering consultancy, who described how he has been inspired to possibly pursue engineering innovation or even engineering research in the future: "I know I enjoyed the research aspect, investigating and creating something new ... ultimately I would like to continue...".

The demonstration has been very successful as it has been presented to thousands of students in the School's Open days, Widening Participation events, Glasgow Science Festival, Glasgow Science Museum and Engineering Hydraulics classes and Design projects, for more than eight years, while it can be also used for engaging aspiring future female engineers, actively promoting diversity in engineering (e.g., see the International Women in Engineering Day, INWED events, where the authors are also actively engaged). As an example, the Head of the Civil Engineering Discipline has been very supportive of the project and has emphasized its importance for the design courses and outreach events, alike:

"Floodopoly is a successful interactive demonstration tool depicting hydrology design projects carried out by Civil Engineers all over the world. It allows students to immediately see the impact of changes in water supply and flood direction on simulated towns and due to the fact that it is portable and adaptable, it has been used at a variety of outreach activities. It was developed by Dr Valyrakis about a decade ago, is an excellent example of research led teaching and has been utilised in a variety of Hydraulics laboratory sessions, School of Engineering Open Days and Glasgow Science Festival activities."

\section{Conclusions}

This study presents the use of a novel approach, namely the "floodopoly" demonstration, in facilitating the teaching of fundamental physical principles around the hydraulic processes that shape the Earth's surface and impact our society, while also informing about engineering designs for flood protection. The design of the "floodopoly" setup replicates the topography of an urbanised town, along with its rivers, and demonstrates the impacts of flooding (induced artificially using small water pumps in a recirculating demonstration flume or custom-made portable sand-box, at the Water Engineering Lab of the University of Glasgow).

A purpose-built survey is used at the end of the design course to assess the effectiveness of the environment and lab demonstrations on enhancing the learning experience of the students. The findings suggest that students with a high level of intrinsic motivation are deep learners and are also top performers in a student-centred learning environment. A supportive teaching environment with a plethora of resources and feedback made available over different platforms has the potential to improve student satisfaction and their learning experience. This can be greatly enhanced by interactive lab activities, as offered by the "floodopoly" demonstration. These results have deep implications about student learning and can be used to further improve the design and delivery of water engineering 
courses in the future. Depending on resources, technical support and expertise available, it is expected that the physical demonstration can become even more engaging if it is combined with modern technological advances, such as augmented reality (AR), to enhance the visual elements of flood impacts and render the activity even more interactive.

Author Contributions: Conceptualization, design, methodology, conduct, formal analysis, visualisation, supervision, project administration, funding acquisition and writing-original draft preparation M.V.; writing-review and editing, M.V., G.L., E.K. and M.C. All authors have read and agreed to the published version of the manuscript.

Funding: Funding from the University of Glasgow's, Chancellor's Fund is gratefully acknowledged in generating improved versions of "floodopoly".

Acknowledgments: The help of the Water Engineering Lab Technician, Tim Montgomery, in constructing the tank and sand-box for "floodopoly", is greatly acknowledged.

Conflicts of Interest: The authors declare no conflicts of interest.

\section{References}

1. Bonwell, C.C.; Eison, J.A. Active Learning: Creating Excitement in the Classroom. In ASHE-ERIC Higher Education Report; School of Education and Human Development, George Washington University: Washington, DC, USA, 1991; p. 104, ISBN 1-878380-08-7.

2. Bonwell, C.C.; Sutherland, T.E. The active learning continuum: Choosing activities to engage students in the classroom. New Dir. Teach. Learn. 1996. [CrossRef]

3. Reynolds, $\mathrm{O}$. An experimental investigation of the circumstances which determine whether the motion of water shall be direct or sinuous, and of the law of resistance in parallel channels. Proc. R. Soc. Lond. 1883, 35, 84-89. [CrossRef]

4. King, A. Improving lecture comprehension: Effects of a metacognitive strategy. Appl. Cogn. Psychol. 1991, 4, 331-346. [CrossRef]

5. Chanson, H. Enhancing Students' Motivation in the Undergraduate Teaching of Hydraulic Engineering: Role of Field Works. J. Prof. Issues Eng. Educ. Pract. 2004, 130, 259-268. [CrossRef]

6. De Jong, T.; Sotiriou, S.; Gillet, D. Innovations in STEM education: The Go-Lab federation of online labs. Smart Learn. Environ. 2014, 1, 3. [CrossRef]

7. Koretsky, M.; Amatore, D.; Barnes, C.; Kimura, S. Education of student learning in experimental design using a virtual laboratory. IEEE Trans. Educ. 2008, 51, 76-85. [CrossRef]

8. Xiang, S.; Wang, L.C. VGLS: A virtual geophysical laboratory system based on C\# and viustools and its application for geophysical education. Comput. Appl. Eng. Educ. 2017, 25, 335-344.

9. Mirauda, D.; Erra, U.; Agatiello, R.; Cerverizzo, M. Mobile augmented reality for flood events management. Water Study 2018, 13, 418-424. [CrossRef]

10. Pauniaho, L.; Hyvönen, M.; Erkkilä, R.; Vilenius, J.; Koskinen, K.T.; Vilenius, M. Interactive 3D Virtual Hydraulics. In E-Training Practices for Professional Organizations; Springer: Boston, MA, USA, 2005; Volume 167, pp. 273-280.

11. O'Neill, G.; McMahon, T. Student-centred learning: What does it mean for students and lecturers. In Emerging Issues in the Practice of Learning and Teaching; All Ireland Society for Higher Education (AISHE), Dublin City University: Dublin, Ireland, 2005; p. 173, ISBN -0-9550134-0-2.

12. Valyrakis, M.; Cheng, M. Enhancing learning in geosciences and water engineering via lab activities. EGU Gen. Assem. Conf. Abstr. 2016, 18, EGU2016-17324-1.

13. Jenkins, A.; Healey, M.; Zetter, R. Linking Research and Teaching in Disciplines and Departments; HE Academy: York, UK, 2007; p. 99.

14. Bogaard, A. Small Group Teaching: Perceptions and problems. Politics 2005, 25, 116-125. [CrossRef]

15. Thomas, C.; Reeves, J.; Laffey, M. Design, Assessment, and Evaluation of a Problem-based Learning Environment in Undergraduate Engineering. High. Educ. Res. Dev. 1999, 18, 219-232. [CrossRef]

16. Healey, M. Linking Research and Teaching to Benefit Student Learning. J. Geogr. High. Educ. 2005, 29, 183-201. [CrossRef]

17. Prince, M.J.; Felder, R.M.; Brent, R. Does Faculty Research Improve Undergraduate Teaching? An Analysis of Existing and Potential Synergies. J. Eng. Educ. 2007, 96, 283-294. [CrossRef] 
18. Liu, D.; Valyrakis, M.; Williams, R. Flow hydrodynamics across open channel flows with riparian zones: Implications for riverbank stability. Water 2017, 9, 720. [CrossRef]

19. Gaudio, R.; Tafarojnoruz, A.; Calomino, F. Combined flow-altering countermeasures against bridge pier scour. J. Hydraul. Res. 2012, 50, 35-43. [CrossRef]

20. Ferraro, D.; Tafarojnoruz, A.; Gaudio, R.; Cardoso, A.H. Effects of pile cap thickness on the maximum scour depth at a complex pier. J. Hydraul. Eng. 2013, 139, 482-491. [CrossRef]

21. Valyrakis, M.; Michalis, P.; Zhang, H. A new system for bridge scour monitoring and prediction. In Proceedings of the 36th IAHR World Congress, The Hague, The Netherlands, 28 June-3 July 2015; pp. 1-4.

22. Looney, J.W. Integrating Formative and Summative Assessment: Progress Toward a Seamless System. OECD Educ. Work. Pap. 2011. [CrossRef]

23. Ramsden, P. Learning to teach in Higher Education; Routledge: Oxford, UK, 1992. [CrossRef]

24. Baeten, M.; Kyndt, E.; Struyven, K.; Dochy, F. Using student-centred learning environments to stimulate deep approaches to learning: Factors encouraging or discouraging their effectiveness. Educ. Res. Rev. 2010, 5, 243-260. [CrossRef]

25. Kabilan, M.K.; Ahmad, N.; Abidin, M.J.Z. Facebook: An online environment for learning of English in institutions of higher education? Internet High. Educ. 2010, 13, 179-187. [CrossRef]

26. Lizzio, A.; Wilson, K.; Simons, R. University students' perceptions of the learning environment and academic outcomes: Implications for theory and practice. Stud. High. Educ. 2002, 27, 27-52. [CrossRef]

27. Nicol, D. Transforming Assessment and Feedback: Enhancing Integration and Empowerment in the First Year; First Year Enhancement Theme Report; QAA: Scotland, UK, 2009.

28. Valyrakis, M.; Solley, M.; Koursari, E. Flood risk modeling of urbanized estuarine areas under uncertainty: A case study for Whitesands, UK. Br. J. Environ. Clim. Chang. 2015, 5, 147-161. [CrossRef] [PubMed]

29. Valyrakis, M.; Diplas, P.; Dancey, C.L. Entrainment of coarse grains in turbulent flows: An extreme value theory approach. Water Resour. Res. 2011, 47. [CrossRef]

30. Valyrakis, M.; Diplas, P.; Dancey, C.L. Prediction of coarse particle movement with adaptive neuro-fuzzy inference systems. Hydrol. Process. 2011, 25, 3513-3524. [CrossRef]

(C) 2020 by the authors. Licensee MDPI, Basel, Switzerland. This article is an open access article distributed under the terms and conditions of the Creative Commons Attribution (CC BY) license (http://creativecommons.org/licenses/by/4.0/). 